\title{
Amy Sue Bix \\ Girls Coming to Tech! A History of American Engineering Education for Women
}

Cambridge, Massachusetts:The MIT Press, 2013. 352pp

\section{Kael R. Sharman}

Independent Scholar

Girls Coming to Tech! A History of American Engineering Education for Women is a much-welcomed addition to the history of women in education. Amy Sue Bix is an Associate Professor of History at Iowa State University. For well over a decade, Bix has published frequently on the topic of gender and technology. Bix now brings to the body of literature on the history of women in education a sense of the lived impact of exclusion and the determination required of the individual women who demanded change. Girls Coming to Tech! is representative of the author's expertise and talent.

The book covers the late nineteenth and most of the twentieth centuries, using three case studies: Georgia Tech, Caltech, and MIT. Bix explains that in each of these institutional case studies, she intends to "examine the issues and tensions...through the voices of numerous female engineering students and those who interacted with them within certain historical contexts" (1). Girls Coming to Tech achieves this goal admirably.

Chapter 1 provides historical background, exploring the many initial instances in which women managed to infiltrate engineering programs. These isolated examples represented the exceptions to the tradition of excluding women. Women's "invasion" of engineering education programs from the late 1870 s to the late 1930 s elicited a range of responses, from mere annoyances for the women to acts of violence. Bix presents Georgia Tech, Caltech, and MIT as contrasting examples that highlight the importance of institutional climate. The key factors in male responses to female incursions were institutional history and character, geographical context and era, and the political and personal inclinations of key figures in college leadership, including students, alumni, professors, administrators, and the general public. Bix uses the interactions among these features to articulate the meaning of women's experiences in 
male territory and to highlight how female students permanently changed the social, intellectual, and institutional nature of American engineering programs.

Bix's detailed case studies bring to the fore the key meanings and changes in the factors she studies. She contrasts the differing contexts that led to the admission of women to engineering faculties at the three institutions at different points in time. For instance, facing internal opposition from traditionalists, Georgia Tech admitted women in 1952 to avoid a court case. Different factors were in play at Caltech, which admitted women in 1968 in the interest of male student socialization and entertainment. MIT admitted women much earlier than its Western and Southern competitors - beginning in the 1870 s - but treated women's education as a minor afterthought. Feminist-era activists in the 1960s and 1970s pushed the school to welcome more women and to take their talent seriously.

The varied changes at institutions, situated within the broader educational and social context of United States, continued to result in an increase of women's presence in the field of engineering. Bix's final chapter offers an account of how women's enrollment in American undergraduate engineering programs gradually rose from rare invaders to a small but growing proportion of graduates. "Of all engineering bachelor's degrees that were issued in the United States in the academic year 2010-11," Bix notes, "18.4\% went to women" (287). Bix also reports that "Across all disciplines ranked by the U.S. Department of Education, engineering still graduated the lowest share of women" in 2008 (288). While the number of women in engineering has risen, US National Science Foundation data indicates there is still much room for improvement in the twenty-first century.

In trying to account for this disparity, we would expect recent history to provide some answers. It was not until the second half of the twentieth century that women began to make inroads into engineering programs at US universities and colleges. Staying within the vast analytical time frame of this study, Bix contends that the root of the problem is that "engineering had been historically associated with the military; it had been associated with construction jobs, building the Erie Canal, building railroads; associated with industry, machine shops - by and large those were not places where women were supposed to be, so there was no reason to teach women engineering. So more so than either science or medicine, engineering was always paired with masculinity" (4).

Bix's study provides a good analysis of the historical background that set the scene for the ongoing tension that faced women in engineering. However, the book does not include much discussion of gender-technology associations. Could extant theoretical perspectives on gender and technology be relevant to the American situation? Does the "invasion" story have anything to do with the place of women in wider society, apart from the stereotype that engineering "belonged to men"? A more explicit discussion of the historical links between gender and technology, and of the various perspectives and theories that explain the links, would have benefited Bix's analysis. The history of women's exclusion from technological development has been explored by authors such as Cynthia Cockburn in Machinery of Dominance: Women, Men and Technical Know-How (1984), an author whose work Bix mentions only briefly. The 
historical exclusion of women in education has been discussed extensively by David Noble and Gerda Lerner as well. Their insights on the pairing of masculinity and technology along with the exclusion of women from education would have been helpful in providing a deeper historical context for why engineering programs have been particularly resistant to welcoming women.

The strength of Bix's book lies in bringing into focus, through the lens of the history of women in engineering, the dramatic revolution that has occurred in American institutions, as well as the social assumptions and the individual lives that made that revolution possible. 